misunderstood, I should feel obliged if you would allow me space for the following explanatory remarks.

My object, as clearly expressed in your report, was to point okt the diagnosis between the curable and incurable cases of lateral curvature; and in so doing I especially dwelt upon "the diagnosis between functional and structural deviations." I stated that no lateral curvature could exist without rotation of the bodies of the vertebræ, and that this rotation necessarily implies the existence of certain structural changes affecting the intervertebral cartilages and oblique articulating processes, and at a later period also the bodies of the vertebræ. I made rotation the test of the existence of true lateral curvature; and for the diagnosis of rotation of the bodies of the vertebræ relied upon the posterior projection of the angles of the ribs on one side in the dorsal region, or of the transverse processes in the lumbar region; the angles of the ribs or the transverse processes of the opposite side receding. If there is no rotation, I assume that there is no real curvature or any structural changes, and that any deviation which may apparently exist as lateral curvature is simply a functional affection, which may, as a general rule, be cured by recumbency and gymnastics; and in these cases I am opposed to mechanical treatment. When rotation, with its structural changes, exists, and constitutes what I conceive to be true lateral curvature, I believe it to be curable only when the affection is slight, of recent formation, and occurring in growing girls or boys. I am convinced that, as rotation advances, so the affection becomes incurable, as I observed, "by any and every method of treatment," the structural changes not admitting of removal or repair; and that " to arrest the increase of curvature, or to produce such improvement as the cases admitted of, it was indispensably necessary to use firm mechanical support."

I am, Sir, your obedient servant,

Henrietta-street, Cavendish-square, Feb. 17th, 1866 Winliam ADams.

\section{VENTILATION OF SEWERS.}

\section{To the Editor of The Lancex.}

SrR,-In your number of the loth inst. you commented on the proceedings of the Metropolitan Board of Works upon the above subject; but as I feel that you have no desire or occasion to found your arguments in favour of sanitary measures upon erroneous reports or mistaken opinions, allow me to offer one or two corrections affecting the subject.

The proposal was to offer a premium for the best plan, \&c. The amendment was to postpone the subject; which, you state, after being proposed and seconded, "was supported by a third speaker, Mr. Evans, who was of opinion that when the main-drainage works were completed there would be such a rapid flow through the sewers that the generation of offensive gases would be prevented." The truth is that I spoke generally on the subject before any amendment was proposed, and therefore not in support of it. I never said the generation of deleterious gases would be prevented altogether, as you would infer; but my argument was to the purpose of proving that the evil had already been diminished, and would doubtless be further abated when the several parishes had completed the reconstruction of their principal sewers, in which they were now actively engaged, by enlarging, deepening, and giving to them a greater inclination towards the great outfalls. I made one observation only after the amendment was proposed, and that to call attention to the Registrar-General's last report" that the rate of mortality in the metropolis had fallen from 26 to 24 per 1000 as compared with the corresponding period of last year; and that the health of London was better than that of any of the other large towns, and was only one above the average (23) of the whole kingdon.."

You also imply that some members of the Board rest on the hope that the completion of the main-drainage works will prevent the formation of the gases in the sewers. I believe I can state, without fear of contradiction, that not one member entertains such a "chimera:" all are fully aware and anxious on the subject. Individuals offer suggestions, and treat the matter as one of ease and simplicity; bat, with the knowledge the members have of the large amount of evidence given upon the subject by all the first chemists and engineers of the day, they cannot but believe, with Mr. Faraday, that "the subject is beset with great difficulties." And the Board have also faith in the able services of their engineer, Mr. Bazalgette, who, in his report of last month, after enumerating the various opinions, plans, and results of experiments on the subject, con- cludes " that the most efficacious and most universally applicable mode of preventing the escape of noxions gases is so to construct the sewers that a continuous flow shall be kept up in them, and provide them with a sufficiently copious supply of water that the decomposing matter within them shall be diluted and instantaneously removed, and not allowed to settle and ferment in the sewers. Much has already been effected in the ventilation of the London sewers by the abolition of the tide-locked and stagnant sewers, and much more may be accomplished by the introduction of a more copious supply of water - a desideratum also otherwise so greatly needed for the necessities and comfort of the inhabitants of the metropolis."

I must add that Mr. Miller's experience, related at length in your commentary, applied to the state of things upwards of ten years ago, before the Metropolitan Board of Works was established. The higher tribunal to which you trust Mr. Miller may carry this subject have repeatedly had it before their committees, and in their reports could only acknowledge the difficulties of the subject, and so remitted it to the Metropolitan Board of Works, whose efforts, I may say, have not been without effect.

In conclusion, allow me to add that this important subject is at the present time engaging the attention of several district surveyors, as well as the engineers of the Board; and the most progressive sanitarian need entertain no fear that the question will remain in statu quo without discussion and experiment.

I am, Sir, yours obediently,
BENJ. EvANS, F.R.C.S.,
Member of the Metropolitan
Beare House, Brixton,
Eeb. 14th, 1866.

\section{O N S Y P H I L I Z A T I ON.}

To the Editor of The LANCET.

SiR, - Of the five patients who subjected themselves to this method of treatment in St. Bartholomew's Hospital, one quitted the hospital, uncured, of her own accord. Of the remaining four, all of whom discontinued the treatment about the end of the second month, two are much in the same state as if they had been treated in the usual way. Of the remaining two, one, a young girl admitted with discharge from the vagina and superficial ulceration, has since suffered from ulceration of the fauces, and verruce about the anus; the other has had a severe cerebral seizure, as if there had been inflammation of the dura mater and effusion of fluid on the brain; her sight became dim, her look wild, and she lost power over the limbs. The patients are still in the hospital.

I am no "mercurialist," but I cannot conclude without the following remarks:-Each surgeon at St. Bartholomew's Hospital has thirteen beds for female venereal patients, making a total of fifty-two. Our late respected colleague, Mr. Lawrence, treated his cases on the "mild mercurial" plan; and it is strange that he cured more cases than the others.

In 1863 the cases admitted numbered 364, of which 224 were treated by mercury. In 1864 the admissions were 365 , of which 200 were treated by mercury ( 75 by inunction).

I remain, Sir, your obedient servant,

Queen Anne-st., Cavendish-sq., Feb. 1866. HOLMES COOTE.

\section{策arlimmontany andulligente.}

\section{HOUSE OF LORDS.}

Feb. 16TH.

PRISONS' REGULATIONS.

Or the motion of Lord CARNARVoN a return was agreed to of the instructions issued by the Home Secretary in relation to the Prisons' Act.

$$
\text { FEB, 19TH. }
$$

CATTLE DISEASES BILL.

On the motion of Earl Granvilue the Cattle Diseases Bill was read a second time, and the standing orders having been suspended the House went into committee on the Bill.

The Earl of AIRLIE moved an amendment to the 12 th clause giving to the local authorities a discretionary power to slaughter or restrain from slaughtering animals certified to be recovering from disease.

The proposal gave rise to some debate, in which the Duke of ARGYLL, the Earl of DERBY, the Duke of RICHMOND, and 